\title{
Review
}

\section{Pentraxins as key disease markers for periodontal diagnosis}

\author{
Rahul Kathariya ${ }^{\mathrm{a}, *}$, Hansa Jain ${ }^{\mathrm{a}}$, Dnyneshwari Gujar ${ }^{\mathrm{a}}$, Archana Singh ${ }^{\mathrm{a}}$, Himanshu Ajwani ${ }^{\mathrm{a}}$ and \\ Devendra Mandhyan ${ }^{\mathrm{b}}$ \\ ${ }^{a}$ Department of Periodontics and Oral Implantology, Dr. D.Y. Patil Dental College and Hospital, Pimpri, Pune, \\ India \\ ${ }^{\mathrm{b}}$ Department of Prosthodontics, Chandra Dental College, Safedabad, Lucknow, India
}

\begin{abstract}
Periodontal diseases are characterized by a complex set of biologic interactions between a diverse and dynamic microbial ecosystem and the host's multifaceted and responsive immune and inflammatory machinery. Such interactions between microbial pathogens and various host response systems play a critical role in the development and progression of periodontal disease via the release of inflammatory and immune mediators. Advances in periodontal disease diagnostic are moving toward methods whereby periodontal risk can be identified and quantified by detecting such inflammatory mediators in its sequential pathophysiology. Pentraxins (PTXs) are classical mediators of inflammation and markers of acute-phase reaction. They are a super family of multifunctional molecules characterized by multimeric structure, divided into "short" PTXs and "long" PTXs. C-reactive protein (CRP) and pentraxin-3 (PTX3) are prototypic molecules of the short and long PTX family, respectively. Evidence suggests that PTXs acts as a non-redundant component of the humoral arm of innate immunity, downstream of, and complementary to, cellular recognition, as well as a tuner of inflammation. CRP is a cheaper biomarker and more readily available in everyday clinical practice compared with other inflammatory markers, on the other hand, PTX3 is believed to be the true independent indicator of disease activity and could have clinical implication in diagnosing the "at site" inflammatory status of the periodontal disease. These pentraxins are sensitive and specific in the diagnosis and prognosis of chronic diseases. Thus the pentraxins could be used as preferred biomarkers in periodontal disease diagnosis.
\end{abstract}

Keywords: Pentraxins, biomarkers, C-reactive protein, pentraxin-3, periodontal disease

\section{Introduction}

The incidence and rate of progression of periodontal diseases depends on the complex interactions between periodontopathic bacteria and cells of host immune system [1]. The interactions between the bacteria and the host are mediated by cytokines and chemokines, produced by both the resident and emigrant cells at the site of inflammation [2]. The bacterial lipopolysac-

*Corresponding author: Dr. Rahul Kathariya, Department of Periodontics and Oral Implantology, Dr. DY Patil Dental College and Hospital, Pimpri, Pune-411018, India. Tel.: +91 8983370741; E-mail: rkathariya@gmail.com. charides (LPS) and other virulence factors activates various pro-inflammatory signals and a variety of innate immune cells to produce numerous cytokines and acute phase proteins [3] (APPs), that are instrumental in generating a host mediated tissue destructive responses [4].

Periodontal clinical diagnosis is made by numerous traditional measures like visual examination, tactile appreciation, bleeding on probing, periodontal pocket depth, attachment level, and radiographic assessment of alveolar bone loss are still popular and universally used [5]. Albeit, easy to use, cost-effective and relatively noninvasive visual and tactile methods, requires the disease activity to be present for a while, 
to be appreciated. Clinical attachment loss evaluation using the periodontal probe measures damage from past episodes of destruction and requires a $2-3 \mathrm{~mm}$ threshold change before a site with significant breakdown can be identified. The use of radiography offers a means to detect changes in alveolar bone calcium content but requires a whopping $30 \%$ bone loss before they are identified on the radiographs. The presence of bleeding on probing is still the best disease activity predictor available, but it is not specific enough and thus reveals too many false positives. The absence of bleeding on probing on the other hand is a very precise negative predictor of periodontal disease activity [6]. However, these traditional measures cannot reliably identify sites with ongoing periodontal destruction and does not provide any information of the cause of the condition or patient's susceptibility to disease, whether the disease is progressing/remission or whether the response to therapy will be positive or negative [7]. Moreover these diagnostic methods are not precisely accurate and only allow retrospective diagnosis at one point of time [8].

Advances in periodontal disease diagnostic research are moving toward methods whereby periodontal risk can be identified and quantified by objective measures such as biomarkers. In Periodontal diagnostics, it has been a great challenge to determine biomarkers for screening and predicting the early onset of disease (prognostic tests) or evaluating the disease activity and the efficacy of therapy (diagnostic tests). Hence the need of advanced markers to accurately identify the disease with high sensitivity (to identify the disease in its presence) and specificity (to exclude the disease in its absence) were sought. Acute phase proteins in general come close to fulfill these criteria.

\section{Acute phase proteins}

Any of the plasma proteins whose concentration increases or decreases by at least $25 \%$ during inflammation. APPs include C-reactive proteins (CRP), several complement and coagulation factors, transport proteins, amyloid, and anti proteases enzymes. They help mediate both the positive and negative effect of acute and chronic inflammation including chemotaxis, phagocytosis, protection against oxygen free radicals and tissue repair. In clinical medicine erythrocyte sedimentation rate or serum CRP levels sometime is used as a marker of increased amount of APPs [9]. The serum and gingival crevicular fluid (GCF) concentra- tions of a number of these APPs, which increases rapidly during infection and concentration raise to several hundred folds, and remains elevated throughout infection [10]. Although there have been several proinflammatory APPs implicated in the immunopathology of periodontitis. The APP that receive maximum attention are CRP, plasminogen-activator inhibitor 1 , and fibrinogen [11]. However, some of the most convincing evidence for destruction of the periodontium involves Interleukin (IL) $-1 \beta$ and tumor necrosis factor-alpha (TNF- $\alpha$ ) [12]. Recent novel research suggests IL- $1 \beta$ and TNF $\alpha$ are the most potent inducers of a new PTX called Pentraxin-3 [13]. Short pentraxins are conserved during phylogenesis and no deficiency state of either CRP or Serum Amyloid Protein (SAP) in humans has yet been reported. This possibly indicates that PTXs confer a survival advantage; however, the mechanisms by which they act are not yet defined. Thus the pentraxins promise to be key markers for periodontal disease diagnosis. This is the first review that compiles various PTXs that can be used for diagnosis of periodontal diseases and attempts to throw light on the numerous advantages of these molecules over other biomarkers.

PTXs are a superfamily of multifunctional conserved proteins, some of which are components of the humoral arm of innate immunity and behave as functional ancestors of antibodies (Abs). They are known as classical APP, known to the human race for over a century [13]. PTXs are characterized by a multimeric, usually pentameric structure by the presence in their carboxyl-terminal of a $\sim 200$ aa-long conserved domain, called pentraxin domain. In addition, all the members of this family share an 8 aa-long conserved sequence (HxCxS/TWxS, in which $x$ is any amino acid) in the PTX domain, called pentraxin signature. Some PTXs, together with collectins and ficolins, constitute the humoral arm of innate immunity and behave as functional ancestors of Abs by mediating agglutination, complement activation, and opsonisation. The name "pentraxin" is derived from the Greek word 'Penta' meaning 'five' and 'Ragos' implying 'berries' relating to the radial symmetry of five monomers (pentameric) forming a ring approximately $95 \AA$ across and $35 \AA$ deep. They are considered to be markers of acute phase of inflammation [14] and are classified into "short" PTXs (CRP and SAP) and "long" PTXs (PTX3).

Long PTXs have an unrelated, long amino-terminal domain coupled to the carboxyl- terminal pentraxin domain and differ, with respect to short pentraxins, 
in their gene organization, chromosomal localization, cellular source, and in inducing stimuli and ligandrecognition ability. The classical short pentraxins i.e. CRP and SAP are produced in the liver in response to inflammatory signals, most prominently by interleukin (IL)-6 [15]. On the contrary, PTX3 is produced on exposure to pro-inflammatory stimuli (Toll-like receptor (TLR) engagement and cytokines TNF $\alpha$, IL$1 \beta$.) and specific microbial constituents (LPS, lipoarabinomannans, outer membrane proteins) [16]. As these molecules are recognized as the most important mediators in the periodontal etiopathogenesis, one can expect PTX3, as a reliable biomarker in periodontal disease diagnosis.

CRP is the first described PTX, it binds to pneumococcal C-polysaccharides and is expressed during the acute phase response to bacterial infections [17]. In the 1930s, it was the first purified pattern recognition molecule, which was named after its ability to bind in a calcium-dependent fashion, C-polysaccharide of Streptococcus pneumonia [18]. Hence the name CRP. They are ligands for leukocyte $\mathrm{Fc} \gamma$ receptors. The CRP gene is located on first chromosome. CRP is a potent APPs that regulate innate resistance to microbes and scavenging of cellular debris. CRP is conserved from mammals to arthropods. In Limulus polyphemus, different forms of CRPs and SAP are normal and abundant, they are the constituents of the hemolymph and are involved in recognizing and destroying pathogens [13].

\section{Functions of CRP}

A major function of CRP is its ability to bind phosphocholine and recognize some foreign pathogens as well as phospholipids of damaged cells. It can activate complement system when bound to one of its ligands and can bind to phagocytic cells. An observation suggests that it can initiate the elimination of targeted cells by its interaction with both humoral and cellular immunity. Other proinflammatory effects of CRP include induction of inflammatory cytokines and tissue factor in monocytes. It is said to assist in complement binding to foreign and damaged cells and affect the humoral response to disease [19]. CRP has the ability to prevent the adhesion of neutrophils to endothelial cells by decreasing the surface expression of L-selectin, inhibit the generation of superoxide by neutrophils, and stimulate the synthesis of interleukin-1 (IL-1) receptor antagonist by mononuclear cells [19]. CRP has also been reported to stimulate tissue factor production by human peripheral blood monocytes and has a procoagulant effect. In addition, CRP recruits monocytes by receptormediated chemotaxis into the arterial wall. It colocalizes with foam cells in atherosclerotic lesions [20,21].

It is a type I APP that is produced on stimulus like heat, trauma, infection and hypoxia. It is found in traces in healthy individuals, that is, $<0.3 \mathrm{mg} / \mathrm{L}$ serum. But in case of severe systemic infection its level could exceed $100 \mathrm{mg} / \mathrm{L}$. This marked increase in its level is used extensively as a marker for tracking the course of infection [22]. Thus CRP has been the focus of attention as a key marker of most systemic diseases discovered till date. Its elevated levels predict an increased risk of cardiovascular disease (CVD) by a factor of approximately 2.1 (1.4-2.78) [23]. According to the recommendations of Centre for Disease Control and Prevention (CDC), serum CRP levels of $\leqslant 1 \mathrm{mg} / \mathrm{l}$ are considered as low risk, 1 to $3 \mathrm{mg} / \mathrm{l}$ as average risk, and $\geqslant 3 \mathrm{mg} / \mathrm{l}$ are considered as high risk for the development of CVD [24]. Baseline hs-CRP concentrations in healthy patients have been shown to be one of the most powerful predictors of both long- and short-term cardiovascular risk in both men and women [25-27]. Also, CRP appear to add to the predictive value in lipid screening $[26,28]$.

CRP are considered to be one of the stronger AP proteins that respond rapidly to inflammatory stimuli and their serum levels can increase significantly in all kinds of inflammations [10-13]. Boulman et al. in 2004 reported its correlation with polycystic ovary syndrome (PCOS). High level of CRP were observed in patients suffering from PCOS than the controls [29].

In periodontal inflammation, CRP are considered to be one of the stronger APPs that respond rapidly to inflammatory stimuli and their serum levels can increase several hundred folds. Novel research has shown that measurements of CRP in serum or GCF might help identify a subset of patients who are at higher risk of destructive periodontal diseases or those who are undergoing a process of periodontal breakdown [30]. Although CRP is produced by hepatocytes, there is evidence of it being present in cells associated with acute connective tissue inflammation [32]. The rapid rise of CRP in serum following exposure to interleukin1 , which is a potent bone resorber (found in GCF), made the search of CRP in periodontitis reasonable. Numerous studies have shown a positive association between chronic periodontal infections and elevated CRP levels. These include large-scale, cross-sectional studies [31] and studies analyzing data from the Third 
National Health and Nutrition Examination Survey, which have included over 10,000 patients [32]. Since many years poor periodontal health is been linked to higher systemic CRP levels [33] with a higher sensitivity, specificity and a greater predictive value. Thus is in not surprising that till today, there have been more than 333 studies reported in Medline pertaining to as periodontal disease and CRP [34]. Although CRP is produced by hepatocytes, there is evidence of it being present in cells associated with acute connective tissue inflammation. The rapid rise of CRP in serum following exposure to interleukin-1, which is a potent bone resorber also found in GCF substantiates this fact [35]. It was reported that elevation of CRP in GCF increases the odds of periodontitis [36]. Also, in our previous study we reported the simultaneous elevation of GCF and serum CRP levels in a progressive periodontal disease [37]. Moreover, its levels in GCF of periodontitis patients correlate significantly with systemic disease [38] and periodontal treatment decreased CRP levels significantly as it decreases the inflammatory burden, of the systemic disease. Recently we evaluated the periodontal inflammatory burden index (PIBI) associated with chronic periodontitis. PIBI reduction post non-surgical periodontal therapy correlated significantly with the post therapy CRP levels. (Unpublished data, Kathariya R et al.) [39]. Thus, CRP levels associated with periodontal disease might play a significant role in predicting high-risk patients for the most common diseases of the present era. Periodontal therapy might also lower the risk of severity of these systemic diseases, as it reduces the inflammatory burden, not only in systemically-compromised individuals, but also in otherwise healthy individuals [40].

CRP is a cheaper alternative and more readily available in everyday clinical practice compared with other inflammatory markers, it has a better sensitivity and specificity, its measurement could have clinical implication in diagnosing the "at site" inflammatory status of the patient [41].

SAP is different from serum amyloid A. It is a second and less known member of short PTXs in the PTX super family. SAP is a $25 \mathrm{kDa}$ pentameric protein which shares $51 \%$ sequence homology with CRP. It was first identified as the pentagonal constituent of in vivo pathological deposits called "amyloid" [42]. SAP makes up $14 \%$ of the dry mass of amyloid deposit and is thought to be an important contributor to the pathogenesis of amyloidoses [43]. These conditions are characterized by the ordered aggregation of normal globular proteins and peptides into insoluble fibers which disrupt tissue architecture and are associated with cell death. SAP is thought to decorate and stabilize aggregates by preventing proteolytic cleavage and hence inhibiting fibril removal via the normal protein scavenging mechanisms [44]. SAP is present in human serum at approximately about $65 \mathrm{pg} / \mathrm{ml}$ and does not vary significantly with inflammation [45]. It is relatively stable, even during the early acute-phase response. It is conserved protein in mice and is of little importance in humansHowever recent studies have shown that significantly higher levels of amyloid protein (AP) in periodontitis and gingivitis tissue [46]. It is correlated with the intensity of plasma cell accumulation and the extent of connective tissue matrix degradation. AP was concentrated in the deep connective tissue and perivascular areas; also, the deposition was associated with nerve bundles and, occasionally seen in the extracellular matrix of the lining epithelium. These findings have potential significance in relation to the pathology of chronic periodontitis as AP has been shown to interact in a calcium-dependent manner with a number of ligands including fibronectin, elastic fibres, C-4 binding protein and amyloid fibrils. Also, amyloid-like fibrils (AP) composed of immunoglobulin light chains were extracted from the lesions of chronic periodontitis [47]. However, SAP sustained a reduction at 4 weeks after periodontal therapy [48]. Cho et al. in 2004, observed elevated levels of SAP in cases of nasopharyngeal cancer. The level increased drastically with the disease, correlated with relapse and decreased with chemotherapy [49]. Literature links radiation therapy carried out for the treatment of the carcinoma causes periodontitis, but, lacks proper evidence on linkage between the two [50]. Further research are warranted to correlate nasopharyngeal carcinoma and periodontitis, and its mechanism of cause. In 2008, Bozinovski et al. concluded that CRP is a novel biomarker of acute exacerbation of congestive obstructive pulmonary disease (COPD) [51]. Later in 2009 Deo et al. confirmed the relationship of COPD and periodontitis. The authors claimed periodontitis as a potential risk factor for COPD [52]. The association of SAP with periodontal diagnosis is sparse and need to be explored further.

PTX3 is a recently discovered first identified prototypic long pentraxin in the PTX super family. It is structurally related to (although distinct from) classical short PTXs- CRP and SAP. It has a high degree of conservation from mouse to man. Both resident and innate immunity cells produce PTX3 in peripheral tissues in response to inflammatory cells, bacterial cyto- 
toxins and Toll like receptors (TLR) activation. PTX3 is a first cloned long PTX as an IL- $1 \beta$-inducible gene in endothelial cells and TNF- $\alpha$ stimulated gene in fibroblast [16].

Recent research suggests that, PTX3 expression is induced in response to inflammatory stimuli, including TNF $\alpha$, IL- $1 \beta$ and microbial moieties, such as LPS, lipoarabinomannans, and outer membrane proteins by a variety cell types abundant in periodontal tissue like neutrophils, fibroblasts, monocytes/macrophages, dendritic cells, epithelial cells, endothelial cells and vascular smooth muscle cells, adiposities, dendritic cells etc. [15] in response to inflammatory cytokines and TLR engagement. Hence hypothesizing that, it is elevated in almost all kinds of inflammation and infections in the body and periodontitis is no exception. However, the plasma levels of PTX3 are very low in normal subjects and are raised in inflammatory conditions resulting from a wide range of disease states from infections to autoimmune and/or degenerative disorders [53]. Moreover, PTX3 is produced from vascular endothelial cells and macrophages, its levels may directly reflect the inflammatory status. Because of its extrahepatic synthesis, on contrary to CRP; PTX3 levels are believed to be a true independent indicator of disease activity [54]. Thus, measurements of PTX3 in GCF or plasma may help identify a subset of patients who are at a higher risk for destructive disease, or those patients who are undergoing a process of periodontal breakdown [55]. Ours was the first study to report the use of PTX3 in periodontal disease diagnosis [56], and periodontal disease associated with chronic kidney diseases (CKD) [57]. We found that, greater the amount of periodontal tissue destruction, greater was the mean PTX3 concentration in both GCF and plasma, as its levels correlated positively with all clinical parameters. We also concluded that GCF PTX3 levels could be considered as 'marker of inflammatory activity in periodontal disease' [56]. In the later study, we found strong correlation between PTX3 levels periodontal parameters in patients with periodontitis associated with CKD and concluded that periodontal disease could serve as a risk factor for developing CKD [57].

Recently PTX3 has been detected in various chronic inflammatory conditions, like atherosclerosis [58], and is recognized as an early marker for unstable angina [59] and myocardial infarction [60]. It was found that it is released by the endothelium and by activated myofibroblasts in systemic sclerosis [61]. It was suggested that PTX3 may contribute to the pathogene- sis of atherosclerosis [59], and hence thrombo-embolic events leading to CVDs and CKDs. It is believed to be a true independent indicator of disease activity at sites of inflammation and vasculitis [54]. Also, PTX3 can act as a natural inhibitor of influenza virus [62]. Moreover it was also found to be elevated to its prognostic value in CVD [63], CKD [64], rheumatoid arthritis [65], preeclampsia [66], inflammatory bowel diseases [67], and severe dengue virus infections [68] etc. Recently, it is also recognized as a diagnostic biomarker for lung pathologies. Its diagnostic sensitivity and specificity was found to be similar to other potential biomarkers for lung carcinoma, acute lung injury and acute respiratory distress syndrome [69,70]. Also, circulating levels of PTX3 significantly correlated with the severity of infection in critically ill patients [71]. The evidence that PTX3 could serve as a potential marker of periodontal diagnosis comes from that fact that neutrophils represent a reservoir of prestored PTX3 in its ready for rapid release-specific granules and release it in response to inflammatory signals. Neutrophils arrive early at sites of periodontal destruction and it is believed that tissue loses its cohesiveness only after neutrophil infiltration increases to more than $60 \%$ [72].

PTX4 is a new unique member of the pentraxin superfamily which consists of 470 amino acids. It has been found that human, murine, and rat PTX4 show $30 \%$ identity at the pentraxin domain level with other long pentraxins. Like other members of this family, the gene encoding PTX4 is well conserved from mammals to lower vertebrates. However, PTX4 has a unique pattern of mRNA expression, which is distinct from that of other long pentraxins [13,20]. In a study authors reported that the expression of PTX4 in endothelial cells, leukocytes, monocytes, lymphocytes (B and T), neutrophils, and NK cells. In endothelial cells, monocytes, neutrophils, and lymphocytes, PTX4 expression was very low, and IL-1 or LPS did not induce it [13]. Presently there is only one reported study in Medline on PTX4. So, further studies are required to define its role as a biomarker and its possible relation to periodontitis.

Neuronal PTXs which includes NP1, NP2 and NPR define a specific family of pentraxins. All three have approximately $50 \%$ identity to each other, and each has $20-25 \%$ identity to the smaller acute phase pentraxins (CRP and SAP). It is suggested that NP1, NP2, and NPR mediate a similar function for neurons [73]. NPTXs have been shown to be involved in the excitatory synaptic remodeling. NPTX2 has been implicated 
in long-term neuronal plasticity as well as dopaminergic nerve cell death and NPTX1 in hypoxia-ischemiaand amyloid-b-induced neuronal death [13]. Studies have suggested that, acetylcholine can influence the immune system via the 'cholinergic anti-inflammatory pathway'. This pathway is mediated by the vagus nerve which releases acetylcholine to interact with the $\alpha 7$ subunit of the nicotinic acetylcholine receptor ( $\alpha 7 \mathrm{nAChR})$ on proximate immuno-regulatory cells. Activation of the $\alpha 7 \mathrm{nAChR}$ on these cells leads to down-regulated expression of pro-inflammatory mediators and thus regulates localized inflammatory responses [74]. Further study on this relation may elaborate on alliance between NPTXs and periodontal inflammation.

NP1 is named for their distinct structural organization of five identical subunits arranged noncovalently in pentameric radial symmetry. Recent studies have shown that NPR has a number of different cytoplasmic isoforms that are often associated with the inner side of the plasma membrane, suggesting that neuronal pentraxins also have physiological functions as intracellular proteins [75]. NP1 is a glycoprotein, involved in both synaptogenesis and synaptic remodeling whose expression is restricted to the nervous system. The amino-terminal half of NP1, also NP2, encodes a series of coiled-coil domains that seem to be essential for homomultimerization. Recent studies have shown that potassium depletion produces a marked increase in NP1 protein levels in cerebellar granule neurons [76]. Many dental and periodontal conditions lead to xerostomia, which in turn leads to hypokalemia that might trigger NP1 secretion. Moreover, JG Meechan et al. reported local anesthetic agents used for dental or periodontal surgeries had a significant influence on serum potassium levels [77].

In a study, it was interesting to discover that hypokalemia due to CKD increases NP1 levels [77], and it can be hypothesized that NP1 levels might influence periodontitis. Exclusive expression of NP1 in the central nervous system, its characteristic feature as a secretory protein, and its large molecular size relative to the classical pentraxins suggest that NP1 may have novel unknown functions [78].

NP2 also known as neuronal activity-regulated pentraxin (Narp); gene symbol NPTX2 (11 kb in length) on 7q21.3-q22.1 chromosome is a recently discovered PTX.

NPTX2 promotes neuritic outgrowth and is suggested to mediate uptake of degraded synaptic material during synapse formation and remodeling and cause aggregation of neurotransmitter receptors at synapses. Recent studies have shown the potential role of NPTX2 as a biomarker [79]. Further studies are warranted to evaluate the role of NPTX2 as a biomarker in periodontal disease diagnosis.

NPR is a third member of the NP family, primarily expressed in the central nervous system, and physically associated with NP2 and NP1. The sequence of NPR has significant homology to the classical pentraxins and to neuronal pentraxin 1 and 2 in particular [73]. In a study by Yin et al. in 2009 [80] showed that NPR is a candidate biomarkers in cerebrospinal fluid for neurodegenerative diseases, and that the changes in the cerebrospinal fluid level of NPR may be specific for Alzheimer's disease [81]. Several reports confirm a tieup between periodontal infection and Alzheimers disease. Thus the role of neuronal pentraxins as periodontal biomarker needs to be evaluated [81].

\section{Conclusion}

Pentraxins (PTXs) are classical mediators of inflammation and markers of acute-phase reaction. They are a super family of multifunctional molecules characterized by multimeric structure, divided into "short" PTXs and "long" PTXs, CRP and PTX3 are respective prototypic molecules. Evidence suggests that PTXs acts as a non-redundant component of the humoral arm of innate immunity, downstream of, and complementary to, cellular recognition, as well as a tuner of inflammation. CRP is a cheaper biomarker and more readily available in everyday clinical practice compared with other inflammatory markers, on the other hand, PTX3 is believed to be the true independent indicator of disease activity and could have clinical implication in diagnosing the "at site" inflammatory status of the periodontal disease. These pentraxins are sensitive and specific in the diagnosis and prognosis of chronic diseases like periodontitis. The newly discovered PTXs were hypothesized to be related in periodontal pathophysiology in some or the other ways. Thus the pentraxins could be used as preferred biomarkers in periodontal disease diagnosis.

However, further research is required to assess the levels of different and newer PTXs in periodontal disease and its influence on systemic disorders and its interrelationship. This study contributes to helping health care providers identify and develop ideal biomarkers for periodontal disease diagnosis. Indentifying them at an early stage might prove vital in intervention strategies to reduce patient risks and prevent systemic disease outcomes. 


\section{Conflict of interest}

The authors report no conflict of interests. It is a selffunded research.

\section{References}

[1] Slots J. Subgingival microflora and periodontal disease. J Clin Periodontol 1979; 6: 351-352.

[2] Takeichi O, Haber J, Kawai T. Cytokines profiles of T lymphocytes from gingival tissues with pathological pocket. $J$ Dent Res 2000; 79: 1548-55.

[3] Offenbacher S. Periodontal disease: pathogenesis. Ann Periodontol 1996; 1: 821-878.

[4] Ebersole, Capell D. Acute-phase reactants in infection and inflammatory diseases. Periodontol 2000 2000; 23: 19-49.

[5] Armitage GC. The complete periodontal examination. Periodontol 2000. 2004; 34: 22-33.

[6] Hafajee AD, Socransky SS, Goodson JM. Clinical parameters as predictors of destructive periodontal activity, J Clin Periodontol 1983; 10: 257.

[7] Sanz M, Newman MG, Quirynen M. Advanced diagnostic techniques. In: Carranza's Clinical periodontology, $10^{\text {th }}$ ed Noida: Elsevier Saunders press, 2006; 579.

[8] Lang NP, Tonetti MS. Periodontal diagnosis in treated periodontitis. Why, when and how to use clinical parameters. $J$ Clin Periodontol 1996; 23: 240-250.

[9] Taber's online [homepage on the internet] Taber's Cyclopedic Medical Dictionary, 21st Edition [updated 23 Jun 2009; cited 13 Mar 2011]. Available from: http://www.tabers. com/tabersonline/ub/view/Tabers/143851/27/acute_phase_ protein?q=acutr\%20phase $\% 20$ reactants.

[10] Stashenko P, Obernesser MS, Prostak L, Haffajee AD, Socransky S. Levels of interlukin $1 \beta$ in tissue sites of active periodontal disease. J Clin Periodontol 1991; 18: 548-554.

[11] Mosmann TR, Coffman R. Th1 and Th2 cells: different pattern of lymphokine production lead to different functional properties. Апnи Rev Immunol 1989; 7: 145-173.

[12] Gemmell E, Marshall RI, Seymour GJ. Cytokines and prostaglandins in immune homeostasis and tissue destruction in periodontal disease. Periodontal 2000 1997; 14: 112-143.

[13] Martinez de, la Torre Y, Fabbri M, Jaillon S, Bastone A, Nebuloni M, Vecchi A, Mantovani A, Garlanda C. Evolution of the pentraxin family: The new entry PTX4. J Immunol 2010; 184(9): 5055-64

[14] Garlanda C, Bottazzi B, Bastone A, Mantovani A. Pentraxins at the crossroads between innate immunity, inflammation, matrix deposition, and female fertility. Апnи Rev Immunol 2005; 23: 337-366.

[15] Steel DM, Whitehead AS. The major acute phase reactants: $\mathrm{C}$-reactive protein, serum amyloid $\mathrm{P}$ component and serum amyloid A protein. Immuol Today 1994; 15: 81-87.

[16] Lee GW, Lee TH, Vilcek J. TSG-14, a tumor necrosis factorand IL-1-inducible protein, is a novel member of the pentraxin family of acute phase proteins. J Immunol 1993; 150: 18041812.

[17] Reid MS, Blobel CP. Apexin, an acrosomal pentraxin. J Biol Chem. 1994; 269(51): 32615-20.

[18] Moalli F, Jaillon S, Inforzato A, Sironi M, Bottazzi B, Mantovani A, et al. Pathogen recognition by the long pentraxin PTX3. J Biomed Biotechnol 2011; 2011: 830421.
[19] Gabay C, Kusher I. Acute - Phase Proteins and Other Systemic Responses to Inflammation. N Engl J Med 1999; 340: 448-54. [PubMed: 9971870].

[20] Slade GD, Ghezzi EM, Heiss G, Beck JD, Riche E, Offenbacher S. Relationship Between Periodontal Disease and CReactive Protein Among Adults in the Atherosclerosis Risk in Communities Study. Arch Intern Med 2003; 163: 1172-9. [PubMed: 12767953].

[21] Beck J, Garcia R, Heiss G, Vokonas PS, Offenbacher S. Periodontal Disease and Cardio Vascular Disease. J Periodontol 1996; 67(10 Suppl): 1123-37. [PubMed: 8910831].

[22] Kanaparthy A, Kanaparthy R, Niranjan N. Evaluation of serum C-reactive protein levels in subjects with aggressive and chronic periodontitis and comparison with healthy controls. Dent Res J 2012; 9(3): 261-265.

[23] Ridker PM, Rifai N, Rose L, Buring JE, Cook NR. Comparison of C-reactive protein and low-density lipoprotein cholesterol levels in the prediction of first cardiovascular events. $N$ Engl J Med 2002; 347: 1557-65.

[24] James Beck, Steven Offenbacher Relationship among clinical measures of periodontal disease and their associations with systemic markers. Ann Periodontol 2002; 7: 79-89.

[25] Ridker PM, Cushman M, Stampfer MJ, Tracy RP, Hennekens $\mathrm{CH}$. Inflammation, aspirin, and the risk of cardiovascular disease in apparently healthy men. N Engl J Med 1997; 336: 9739.

[26] Ridker PM, Hennekens CH, Buring JE, Rifai N. C-Reactive protein and other markers of inflammation in the prediction of cardiovascular disease in women. N Engl J Med 2000; 342: 836-43.

[27] Danesh J, Whincup P, Walker M, et al. Low grade inflammation and coronary heart disease: Prospective study and updated meta-analyses. BMJ 2000; 321: 199-204.

[28] Ridker PM, Glynn RJ, Hennekens CH. C-Reactive protein adds to the predictive value of total and HDL cholesterol in determining risk of first myocardial infarction. Circulation 1998; 97: 2007-11.

[29] Boulman N, Levy Y, Leiba R, Shachar S, Linn R, Zinder $\mathrm{O}$, et al. Increased C-reactive protein levels in the polycystic ovary syndrome a marker of cardiovascular disease. J Clin Endocrinol Metab 2004; 89(5): 2160-5.

[30] Johnson NW, Griffiths GS, Wilton JM, et al. Detection of high-risk groups and individuals for periodontal disease. Evidence for the existence of higher groups and individuals and approaches to their detection. J Clin Periodontol 1998; 15: 276-82.

[31] Noack B, Genco RJ, Trevisan M, Grossi S, Zambon JJ, De Nardin E. Periodontal infections contribute to elevated systemic C-reactive protein level. J Periodontol 2001; 72: 12217.

[32] Slade GD, Offenbacher S, Beck JD, et al. AP inflammatory response to periodontal disease in the US population. $J$ Dent Res 2000; 79: 49-57

[33] Bruno G. Loos. Systemic markers of inflammation in periodontitis. J Periodontol 2005; 76: 2106-15.

[34] US National Library of Medicine. National Library of Medicine. 2011. C reactive protein and periodontal disease URL: http://www.ncbi.nlm.nih.gov/pubmed?term $=\mathrm{c} \% 20$ reac tive $\% 20$ protein $\% 20$ in $\% 20$ periodontal\%20disease.

[35] Gewurz H, Mold C, Siegal J, Fiedel B. C-reactive protein and APP response. Adv Intern Med 1982; 27: 345-72.

[36] Fitzsimmons TR, Sanders AE, Bartold PM, Slade GD. Local and systemic biomarkers in gingival crevicular fluid increase odds of periodontitis. J Clin Periodontol 2010; 37(1): 30-6. 
[37] AR Pradeep, RGS Manjunath and Kathariya R. Progressive periodontal disease has a simultaneous incremental elevation of gingival crevicular fluid and serum CRP levels. JICD 2010; 1: 133-138.

[38] Tuter G, Kurtis B, Serdar M. Evaluation of gingival crevicular fluid and serum levels of high-sensitivity $\mathrm{C}$-reactive protein in chronic periodontitis patients with or without coronary artery disease. J Periodontol 2007; 78: 2319-24.

[39] Kathariya A, Dyneshwari G, Bokil S. Association of CRP and periodontal inflammatory burden in periodontitis patients and effect of periodontal therapy on its modulation. (Unpublished data).

[40] Marcaccini AM, Meschiari AC, Sorgi CA, et al. Circulating interleukin-6 and high-sensitivity $\mathrm{C}$-reactive protein decrease after periodontal therapy in otherwise healthy subjects. $J \mathrm{Pe}$ riodontol 2009; 80: 594-602.

[41] Tripepi G, Mallamaci F, Zoccali C. Inflammation markers, adhesion molecules, and all-cause and cardiovascular mortality in patients with ESRD: Searching for the best risk marker by multivariate modeling. J Am Soc Nephrol 2005; 16(1): S83S88.

[42] Cathcart ES, Shirahama T, Cohen AS. Isolation and identification of a plasma component of amyloid. Biochim Biophy Acta 1967; 147: 392-393.

[43] Tennent GA, Lovat LB, Pepys MB. Serum amyloid P component prevents proteolysis of the amyloid fibrils of Alzheimer disease and systemic amyloidosis. Proc Natl Acad Sci 1995 92(10): 4299-303.

[44] Malle E, De Beer FC. Human serum amyloid A (SAA) protein: A prominent acute-phase reactant for clinical practice. Eur J Clin Investig 1996; 26: 427-435.

[45] Skinner M, Vaitukaitis JL, Cohen AS, Benson MD. Serum amyloid $\mathrm{P}$-component levels in amyloidosis, connective tissue diseases, infection, and malignancy as compared to normal serum. J Lab Clin Med 1979; 94(4): 633-638.

[46] Short LL, Zoellner H, Hunter N. Association of amyloid P protein with pathology in periodontal tissues. J Oral Pathol Med 1994; 23(8): 354-7.

[47] Short LL, Zoellner H, Hunter N. Extraction of amyloid-like fibrils from chronically inflamed periodontal tissues. J Oral Pathol Med 1994; 23(8): 358-63.

[48] Behle JH, Sedaghatfar MH, Demmer RT, et al. Heterogeneity of systemic inflammatory responses to periodontal therapy. $J$ Clin Periodontol 2009; 36(4): 287-94.

[49] Cho WC, Yip TT, Yip C, Yip V, Thulasiraman V, Ngan RK, et al. Identification of Serum Amyloid A protein as potentially useful biomarker to monitor relapse of nasopharyngeal cancer by serum proteomic profiling. Clin Cancer Res 2004; 10: 4352.

[50] Sumitsawan Y, Chaiyasate S, Chitapanarux I, Anansuthiwara M, Roongrotwattanasiri K, Vaseenon V, et al. Late complications of radiotherapy for nasopharyngeal carcinoma. Auris Nasus Larynx 2009; 36(2): 205-9.

[51] Bozinovski S, Hutchinson A, Thompson M, Macgregor L, Black J, Giannakis E, et al. Serum Amyloid A Is a Biomarker of Acute Exacerbations of Chronic Obstructive Pulmonary Disease. Am J Respir Crit Care Med 2008; 177(3): 269-78.

[52] Deo V, Bhongade ML, Ansari S, Chavan RS. Periodontitis as a potential risk factor for chronic obstructive pulmonary disease: A retrospective study. Indian J Dent Res 2009; 20(4): 466-70.

[53] Okutani D. The role of long pentraxin 3, a new inflammatory mediator in inflammatory responses. Nihon Rinsho Meneki Gakkai Kaishi 2006; 29:3: 107-113.
54] Fazzini F, Peri G, Doni A, Dell'Antonio G, Dal Cin E, Bozzolo E. et al. PTX3 in small-vessel vasculitides: An independent indicator of disease activity produced at sites of inflammation. Arthritis Rheum 2001; 44: 2841-2850.

[55] Johnson NW, Griffiths GS, Wilton JM, et al. Detection of high-risk groups and individuals for periodontal disease. Evidence for the existence of higher groups and individuals and approaches to their detection. J Clin Periodontol 1998; 15: 276-82.

[56] Pradeep AR, Kathariya R, Raghavendra NM, Sharma A. Levels of Pentraxin-3 in Gingival Crevicular Fluid and Plasma in Periodontal Health and Disease. J Periodontology 2011; 82(5): 734-41.

[57] Pradeep AR, Kathariya R, Sushmarani R, Sharma A, Raghavendra NM. Risk factors for chronic kidney diseases may include periodontal disease: As estimated by the correlations of plasma pentraxin 3 levels: A case control study. Int Urol Nephrol 2012; 44(3): 829-39.

[58] Savchenko A, Imamura M, Ohashi R, et al. Expression of pentraxin 3 (PTX3) in human atherosclerotic lesions. J Pathol 2008; 215: 48-55.

[59] Inoue K, Sugiyama A, Reid PC, et al. Establishment of a high sensitivity plasma assay for human pentraxin 3 as a marker for unstable angina pectoris. Arterioscler Thromb Vasc Biol 2007; 27: 161-167.

[60] Peri G, Introna M, Corradi D, et al. PTX3. A prototypical long pentraxin, is an early indicator of acute myocardial infarction in humans. Circulation 2000; 102: 636-641.

[61] Giuseppe A, Ramirez, Stefano Franchini, Patrizia RovereQuerini, Maria Grazia Sabbadini, Angelo A. Manfredi, Norma Maugeri. The role of platelets in the pathogenesis of systemic sclerosis. Front Immunol 2012; 3: 160.

[62] Reading PC, Bozza S, Gilbertson B, et al. Antiviral activity of the long chain pentraxin PTX3 against Influenza Viruses. $J$ Immunol 2008; 180: 3391-3398.

[63] Latini R, Maggioni AP, Peri G, et al. Prognostic significance of the long pentraxin PTX3 in acute myocardial infarction. Circulation 2004; 110: 2349-2354.

[64] Tong M, Correro JJ, Qureshi AR, et al. Plasma Pentraxin 3 in Patients with Chronic Kidney Disease: Associations with Renal Function, Protein-Energy Wasting, Cardiovascular Disease, and Mortality. Clin J Am Soc Nephrol 2007; 2: 889-897.

[65] Luchetti MM, Piccinini G, Mantovani A, et al. Expression and production of the long pentraxin PTX3 in rheumatoid arthritis (RA). Clin Exp Immunol 2000; 119: 196-202.

[66] Cetin I, Cozzi V, Pasqualini F, et al. Elevated maternal levels of the long pentraxin 3 (PTX3) in preeclampsia and intrauterine growth restriction. Am J Obstet Gynecol 2006; 194: 13471353.

[67] Shingo K, Mitsuko O, Tomaya S, et al. Increased expression of long pentraxin in inflammatory bowel diseases. Dig Dis Sci 2008; 53: 1910-1916.

[68] Albert TAM, Giuseppe P, Tatty ES, et al. Elevated plasma levels of the long pentraxin, Pentraxin 3 in severe dengue virus infections. J Medical Virol 2005; 76: 547-552.

[69] Diamandis EP, Goodglick L, Planque C, Thornquist MD. Pentraxin-3 is a novel biomarker of lung carcinoma. Clin Cancer Res 2011; 17(8): 2395-9.

[70] Mauri T, Coppadoro A, Bellani G, Bombino M, Patroniti N, Peri G, et al. A. Pentraxin 3 in acute respiratory distress syndrome: An early marker of severity. Crit Care Med 2008; 36(8): 2302-8.

[71] Muller B, Peri G, Doni A, et al. Circulating levels of the long 
pentraxin PTX3 correlate with severity of infection in critically ill patients. Crit Care Med 2001; 29: 1404-1407.

[72] Jaillon S, Peri G, Delneste Y, Fremaux I, Doni A, Moalli F, et al. The humoral pattern recognition receptor PTX3 is stored in neutrophil granules and localizes in extracellular traps. $J$ Exp Med 2007; 204(4): 793-804.

[73] Dodds DC, Omeis IA, Cushman SJ, Helms JA, Perin MS. Neuronal pentraxin receptor, a novel putative integral membrane pentraxin that interacts withneuronal pentraxin 1 and 2 and taipoxin-associated calcium-binding protein 49. $J$ Biol Chem 1997; 272(34): 21488-94.

[74] Zoheir N, Lappin DF, Nile CJ. Acetylcholine and the alpha 7 nicotinic receptor: A potential therapeutic target for the treatment of periodontal disease? Inflamm Res 2012; 61(9): 91526.

[75] Abad MA, Enguita M, DeGregorio-Rocasolano N, Ferrer I. Trullas Neuronal pentraxin 1 contributes to the neuronal damage evoked by amyloid-beta and is over expressed in dystrophic neurites in Alzheimer's brain. J Neurosci 2006; 26(49): 12735.

[76] Enguita M, DeGregorio-Rocasolano N, Abad A, Trullas R.
Glycogen synthase kinase 3 activity mediates neuronal pentraxin 3 activity mediates neuronal pentraxin 1 expression and cell death induced by potassium deprivation in cerebellar granule cells. Mol Pharmacol 2005; 67(4): 1237-46.

[77] Meechan JG, Rawlins MD. The effects of two different dental local anesthetic solutions onplasma potassium levels during third molar surgery. OOO 1988; 669 (6): 650-653.

[78] Hossain MA, Russell JC, O'Brien R. J Leterra Neuronal pentraxin 1: A noval mediator of hypoxic-ischemic injury in neonatal brain J Neurosci 2004; 24(17): 4187-96.

[79] Crocker A, España RA, Papadopoulou M, Saper CB, Faraco J, Sakurai T, Honda M, Mignot E, Scammell TE. Concomitant loss of dynorphin, NARP, and orexin in narcolepsy. Neurology 2005; 65(8): 1184-8.

[80] Yin GN, Lee HW, Cho JY, Suk K. Neuronal pentraxin receptor in cerebrospinal fluid as a potential biomarker for neurodegenerative diseases. Brain Res 2009; 1265: 158-70.

[81] Kamer AR, Craig RG, Dasanayake AP, Brys M, GlodzikSobanska L, de Leon MJ. Inflammation and Alzheimer's disease: Possible role of periodontal disease. Alzheimers Dement 2008; 4(4): 242-50. 


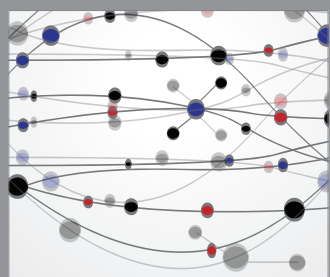

The Scientific World Journal
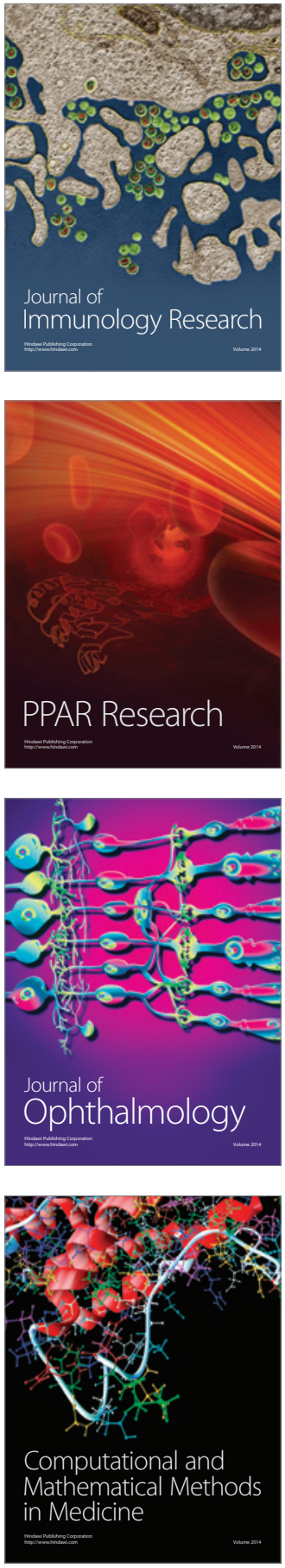

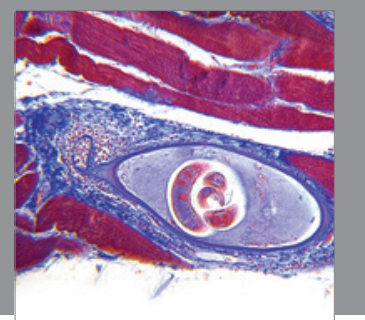

Gastroenterology

Research and Practice
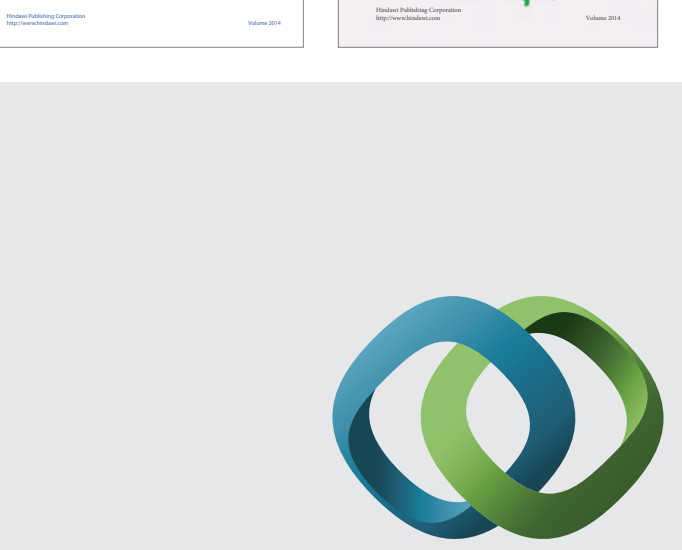

\section{Hindawi}

Submit your manuscripts at

http://www.hindawi.com
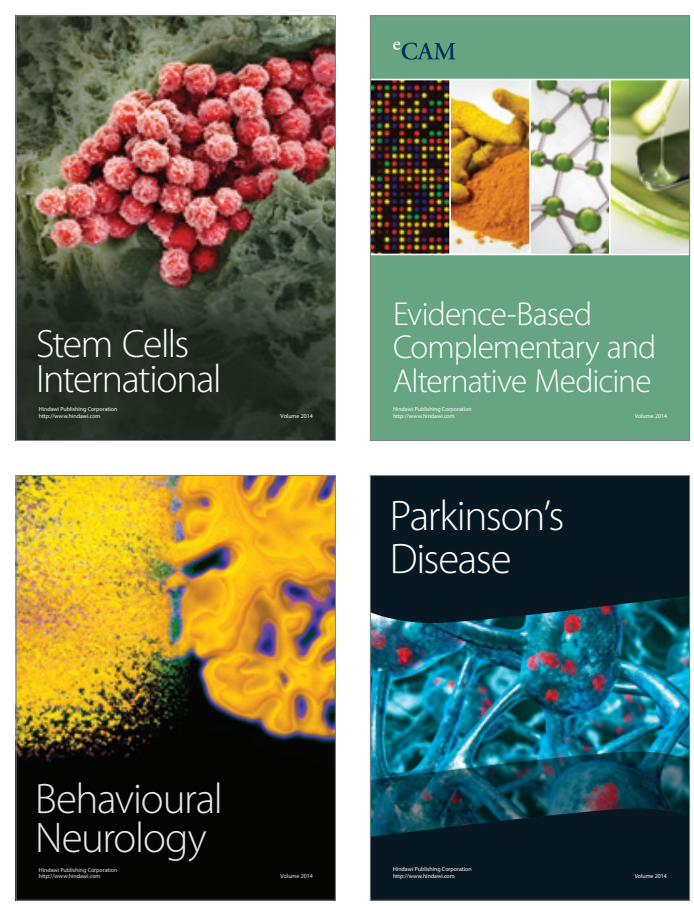

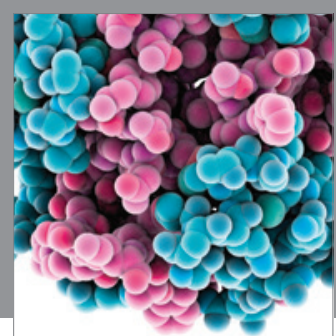

Journal of
Diabetes Research

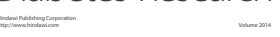

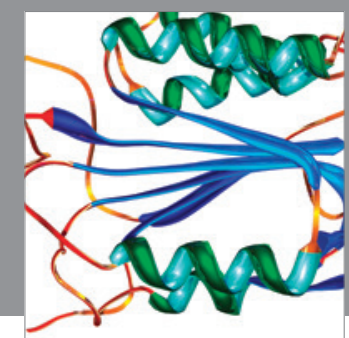

Disease Markers
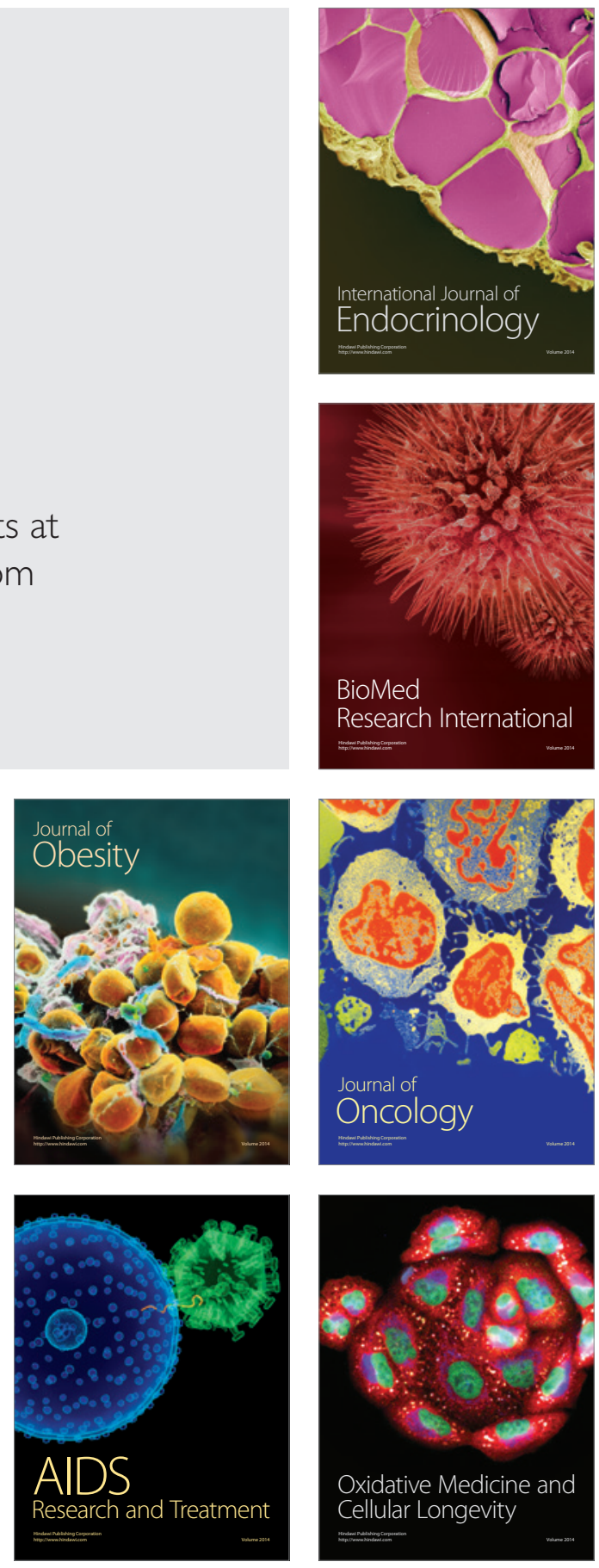